\title{
Maternal Health Care Utilization Among HIV-Positive Female Adolescents in Kenya
}

\begin{abstract}
CONTEXT: Given the health risks of HIV/AIDS and the risks of teenage pregnancy in general, pregnant HIV-positive adolescents in Kenya need maternal health care services that account for their HIV status. However, research on their access to and use of these services is scant.
\end{abstract}

METHODS: To examine maternal health care utilization, pregnancy history data collected in 2009 on 506 pregnancies among 393 HIV-positive female adolescents aged 15-19 enrolled in HIV/AIDS programs in Kenya were analyzed. Multilevel logit models were used to identify the variables associated with use of prenatal care, prevention of motherto-child transmission (PMTCT) of HIV, skilled attendance at pregnancy outcomes and postnatal/postabortion care.

RESULTS: Use of PMTCT services was less common than use of prenatal care among HIV-positive adolescents (67\% of pregnancies vs. $84 \%)$. These adolescents made four or more prenatal care visits in only $45 \%$ of pregnancies. In addition, use of skilled care during or after abortion or miscarriage was low (20\%). The odds of receiving PMTCT services and skilled assistance (for any pregnancy outcome) were higher in Nairobi than in other regions (odds ratios, 3.8 and 2.7, respectively). HIV-positive adolescents were less likely to use maternal health care for higher-order pregnancies than for lower-order pregnancies (0.4-0.6). They were, however, more likely to receive prenatal care and PMTCT services when their husband rather than someone else was responsible for the pregnancy (3.7 and 4.9, respectively).

CONCLUSION: Pregnant, HIV-positive adolescents need maternal health care services-including PMTCT care-that take into account parity, paternity dynamics and regional variations in use.

International Perspectives on Sexual and Reproductive Health, 2011,37(3):143-149, doi: 10.1363/3714311

\section{By Harriet Birungi, Francis Obare, Anke van der Kwaak and Jane Harriet Namwebya}

Harriet Birungi is senior associate, and Francis Obare is senior analyst, both at the Population Council, Nairobi, Kenya. Anke van der Kwaak is health advisor and trainer, Royal Tropical Institute, Amsterdam, Netherlands. Jane Harriet Namwebya is regional senior technical officer, Family Health International, Nairobi, Kenya.
Teenage pregnancy and childbearing present a paradox in many parts of Sub-Saharan Africa. Although many cultures do not approve of premarital teenage sexuality and pregnancy, they still sanction early marriages, which are associated with increased coital frequency and decreased condom use, and hence increased chances of early childbearing. ${ }^{1-3}$ Early marriage is becoming less frequent in many countries in the region; however, these declines are shifting the context of sexual initiation from marital to premarital sex. ${ }^{3-6}$ Compared with other regions of the world, Sub-Saharan Africa continues to have the greatest proportion of teenagers who are mothers. ${ }^{3,7-9}$ At the same time, perhaps because of the cultural view of premarital teenage sexuality and pregnancy and the weakness of health care systems in general, reproductive health services in most cases do not adequately meet the needs of adolescents, including teenage mothers. ${ }^{10-12}$

A number of studies in the developed and developing world have documented worse maternal and child health outcomes among teenage mothers than among older mothers, including increased risks of preterm delivery, low birth weight, neonatal mortality and late spontaneous or induced abortions. This disparity has been attributed to teenagers' physiological immaturity, lower use of prenatal and delivery care services, lower socioeconomic status and higher rates of unintended pregnancy. ${ }^{13-21}$ These disad- vantages are likely to be exacerbated in low-resource contexts such as Sub-Saharan Africa; indeed, profound disparities exist even in urban areas with relatively good health care services. ${ }^{19,20,22-24}$

The high HIV prevalence in parts of Sub-Saharan Africa further complicates the reproductive health outcomes of pregnant teenagers: Obtaining access to relevant services, such as prenatal care, skilled attendance and prevention of mother-to-child transmission (PMTCT) of infection, is likely more difficult. Because of their age, teenage mothers may have to deal with disapproving health care providers; in addition, those living with HIV may face stigma and discrimination in health care settings. ${ }^{25,26}$ Nonetheless, with the increased availability of antiretroviral treatment and emphasis on treatment, care and prevention, maternal and child health outcomes should improve for HIV-positive women, including adolescents. However, emerging evidence indicates that the existing HIV/AIDS treatment, care and support programs in the region do not ask their adolescent clients about their sexual and reproductive health needs because most service providers advise these clients to refrain from or postpone sexual intercourse. ${ }^{27-29}$ This represents a missed opportunity for systematically identifying and addressing the reproductive health concerns of HIV-positive adolescent clients.

Given the poor maternal and child health outcomes of 
TABLE 1. Percentage distribution of HIV-positive female adolescents enrolled in HIV/AIDS programs and female adolescents in the general population, by selected characteristics, Kenya, 2008-2009

Characteristic

$\begin{array}{ll}\text { HIV-positive } & \text { General } \\ (\mathrm{N}=757) & \text { population† } \\ & (\mathrm{N}=952)\end{array}$

\begin{tabular}{|c|c|c|}
\hline \multicolumn{3}{|l|}{ Age } \\
\hline $15-17$ & 35.0 & 59.4 \\
\hline $18-19$ & 65.0 & 40.7 \\
\hline \multicolumn{3}{|l|}{ Study site } \\
\hline Coast & 21.0 & 24.9 \\
\hline Nairobi & 32.1 & 13.9 \\
\hline Nyanza & 30.1 & 30.8 \\
\hline Rift Valley & 16.8 & 30.5 \\
\hline \multicolumn{3}{|l|}{ Education } \\
\hline None & 2.9 & 6.2 \\
\hline Primary & 68.0 & 62.1 \\
\hline$\geq$ secondary & 28.1 & 31.7 \\
\hline Missing & 0.9 & 0.0 \\
\hline \multicolumn{3}{|c|}{ Currently married/living together } \\
\hline Yes & 12.4 & 1.4 \\
\hline No & 87.6 & 98.6 \\
\hline Total & 100.0 & 100.0 \\
\hline
\end{tabular}

tFigures are based on the 2008-2009 Kenya Demographic and Health Survey (KDHS) for the four regions from which the HIV-positive adolescent sample was drawn. Note: Percentages may not total 100.0 because of rounding.

adolescents in the region, it seems reasonable to assume that pregnant, HIV-positive teenagers have difficulty obtaining access to appropriate maternal health services. However, research in this area is limited. Using unique pregnancy history data collected from HIV-positive adolescent females who were receiving treatment, care and support services from various HIV/AIDS programs in four regions of Kenya, this article examines the use of maternal health care services by this subset of the population. First, we describe the distribution of pregnancies among HIVpositive adolescents by maternal background characteristics and use of health care services. Subsequently, we examine the variables associated with maternal health care use in the group of HIV-positive adolescents, with specific focus on prenatal care, PMTCT services, skilled attendance and postnatal care.

\section{DATA AND METHODS}

Data

The data are from a study conducted in 2009 among HIVpositive male and female adolescents aged 15-19 in the regions with the highest HIV prevalence in KenyaNyanza, Nairobi, Rift Valley and Coast provinces. Among 15-49-year-olds, the HIV prevalence in these regions is $14 \%, 7 \%, 5 \%$ and $4 \%$, respectively, while prevalence among $15-19$-year-olds is $5.8 \%, 0.3 \%, 0.7 \%$ and $0.8 \%$. In Kenya overall, HIV prevalence is $6.3 \%$ among adults and $1.7 \%$ among adolescents. ${ }^{30}$

The study involved a quantitative survey and qualitative interviews with HIV-positive adolescents who were aware of their serostatus and were willing to participate, as well as focus group discussions with a subset of the same participants and unstructured interviews with providers working with this population. The participants were identified and recruited through existing programs for orphaned and vulnerable children, comprehensive care centers, youth counseling centers and voluntary counseling and testing centers in the four provinces. Most centers were located in urban and periurban areas although many, especially those in periurban areas, served clients from rural areas as well. Service providers (counselors, community health care workers and social workers) who interacted with the adolescents helped identify respondents. Written consent was obtained from participants before interviews were conducted. For adolescents aged 15-17, written consent was obtained from their parent or guardian and then from the adolescents themselves. For those aged 18-19 and those aged 15-17 who were living alone, married or taking care of siblings, only individual written consent was obtained. Ethical and research clearance for the study was granted by the institutional review board of the Population Council, the Research Ethics Committee of the Royal Tropical Institute, the Ethics Review Committee of the Kenya Medical Research Institute and the Kenya National Council for Science and Technology.

This article uses only the data from the quantitative survey, in which structured interviews were conducted by research assistants aged 18-24 who had received training on study procedures, data collection and research ethics. The survey tool was adapted from one used for a similar study in Uganda. ${ }^{27}$ It was then translated into Kiswahili (Kenya's national language) and Dholuo, the dominant language spoken in Nyanza province. The interview setting was agreed on by the research assistant and the respondent.

The survey collected information on respondents' background characteristics, highest level of education (no schooling, primary school, and secondary school and above), access to information and support services, relationships and dating, sexual behavior and desires, knowledge and use of contraceptive methods, age at first pregnancy (in single years), pregnancy history and childbearing experiences, experiences of physical and sexual violence, whether the respondents felt they were discriminated against because of their serostatus (perception of stigma) and issues of self-esteem.

A total of 1,070 HIV-positive adolescents were identified as eligible to participate in the study, and interviews were completed with 1,059 individuals. Of the 11 adolescents who did not complete interviews, one declined, and the remaining were unable to continue because of emotional breakdown or were still unaware of or in denial about their serostatus.

The number of female respondents who completed the survey was 757 . Of these, $77 \%$ (586) had ever had sexual intercourse. Three hundred and ninety-three of those who had ever had intercourse had been pregnant, while 24\% (95) of those who had been pregnant had experienced multiple pregnancies. The total number of pregnancies reported was 506; for each pregnancy, respondents were asked de- 
TABLE 2. Percentage distribution of pregnancies among HIV-positive female adolescents, according to selected characteristics and use of maternal health services, Kenya

\begin{tabular}{|c|c|c|c|}
\hline Characteristic & $\begin{array}{l}\% \\
(\mathrm{~N}=506)\end{array}$ & Characteristic & $\begin{array}{l}\% \\
(\mathrm{~N}=506)\end{array}$ \\
\hline Age & & Unintended pregnancy & \\
\hline $15-17$ & 14.8 & Yes & 73.9 \\
\hline \multirow[t]{2}{*}{$18-19$} & 85.2 & No & 25.5 \\
\hline & & Missing & 0.6 \\
\hline \multicolumn{4}{|l|}{ Study site } \\
\hline Coast & 14.4 & Prenatal care & \\
\hline Nairobi & 36.2 & Yes & 84.0 \\
\hline Nyanza & 36.8 & No & 15.4 \\
\hline Rift Valley & 12.6 & Missing & 0.6 \\
\hline \multicolumn{2}{|l|}{ Education } & $\geq 4$ prenatal visits & \\
\hline None & 5.3 & Yes & 45.1 \\
\hline Primary & 70.6 & No & 38.9 \\
\hline zsecondary & 23.3 & No visit & 15.4 \\
\hline Missing & 0.8 & Missing & 0.6 \\
\hline \multicolumn{2}{|l|}{ Currently married/living together } & PMTCT care & \\
\hline Yes & 26.5 & Yes & 66.8 \\
\hline \multirow[b]{2}{*}{ 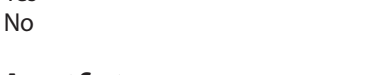 } & 73.5 & No & 32.6 \\
\hline & & Missing & 0.6 \\
\hline \multicolumn{4}{|l|}{ Age at first pregnancy } \\
\hline$<15$ & 11.5 & Pregnancy outcome & \\
\hline $15-17$ & 67.6 & Full-term live birth & 74.3 \\
\hline 18-19 & 20.4 & Preterm live birth & 10.7 \\
\hline \multirow[t]{2}{*}{ Don't remember/missing } & 0.6 & Miscarriage/stillbirth & 4.9 \\
\hline & & Ended it/aborted & 4.2 \\
\hline Pregnancy/order & & Still pregnant & 5.3 \\
\hline 1 & 73.7 & Missing & 0.6 \\
\hline 2 & 21.7 & & \\
\hline 3 & 3.6 & Skilled attendance $\neq$ & \\
\hline \multirow[b]{2}{*}{ 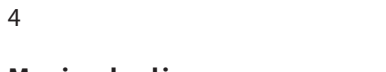 } & 1.0 & Yes & 72.9 \\
\hline & & No & 27.1 \\
\hline \multicolumn{4}{|l|}{ Man involved in pregnancy } \\
\hline Boyfriend/fiancé & 66.2 & Postnatal/postabortion care‡ & \\
\hline Husband & 24.7 & Yes & 82.8 \\
\hline \multirow{3}{*}{ Missing } & 8.7 & No & 17.2 \\
\hline & 0.4 & & \\
\hline & & Total & 100.0 \\
\hline
\end{tabular}

†Friend, acquaintance or stranger. $¥$ Among the 476 pregnancies that had ended (live births, stillbirths, miscarriages or abortions). Notes: PMTCT=prevention of mother-to-child transmission (of HIV). Percentages may not total 100.0 because of rounding.

tailed questions on whether it was intended, the relationship to the man who was responsible (husband, boyfriend, fiancé, friend, acquaintance or stranger), use of prenatal care services, the outcome, the place of delivery or pregnancy termination, and use of family planning after delivery or pregnancy termination. Use of maternal health care services was measured by five dichotomous outcomes-receiving prenatal care; making four or more prenatal care visits $(0-3, \geq 4)$; receiving PMTCT services; receiving skilled assistance (being assisted by a doctor, nurse or facility midwife during delivery or induced or spontaneous abortion); and receiving postnatal/postabortion care services.

\section{Analysis}

The data are hierarchical, and pregnancies are clustered within individual adolescent mothers identified from the same HIV/AIDS treatment, care and support facility. The nature of the data requires an analysis technique that accounts for unobserved characteristics of pregnancies to the same mother as well as of individuals identified from the same facility. The analysis therefore entails estimation of randomintercept multilevel logit models using Stata ${ }^{31}$ to predict use of maternal health care services. *

The first two models include as covariates the age at first pregnancy, study site, the highest level of education of the mother, pregnancy order, relationship to the man who was responsible for the pregnancy, an indicator of whether the respondents felt they were discriminated against because of their serostatus (perception of stigma) and whether the pregnancy was intended. In addition to these, the next three models include prenatal care visits as a control.

\section{RESULTS}

\section{Characteristics of the Sample}

Because the HIV-positive adolescents participating in the study are likely to differ from adolescents in the general population, we provide data from the Kenya Demographic and

*The basic model is expressed as follows:

$$
\log i t\left(\pi_{i j k}\right)=X_{i j k} \beta+\mu_{j k}
$$

where $\pi_{\text {ijk }}$ is the probability of a given outcome for pregnancy or birth $i$ to individual mother $j$ identified from facility $k, X_{\mathrm{ijk}}$ is the vector of covariates, $\beta$ is the associated vector of fixed parameters and $\mu_{\mathrm{jk}}$ are the unobserved characteristics of individual mothers $j$ from the same facility $k$ that might be correlated with the outcomes of interest. 


\begin{tabular}{|c|c|c|c|}
\hline Variable & $\begin{array}{l}\text { Any prenatal } \\
\text { care }\end{array}$ & $\begin{array}{l}\geq 4 \text { prenatal } \\
\text { visits }\end{array}$ & $\begin{array}{l}\text { РMTCT } \\
\text { services }\end{array}$ \\
\hline Age at first pregnancy (in yrs.) & $1.1(0.9-1.3)$ & $1.0(0.8-1.2)$ & $1.2(1.0-1.5)$ \\
\hline \multicolumn{4}{|l|}{ Study site } \\
\hline Nyanza (ref) & 1.0 & 1.0 & 1.0 \\
\hline Coast & $0.3(0.1-0.8)^{*}$ & $1.3(0.5-3.3)$ & $0.8(0.2-2.4)$ \\
\hline Nairobi & $0.7(0.3-1.7)$ & $0.5(0.2-1.0)$ & $3.8(1.1-12.7)^{*}$ \\
\hline Rift Valley & $0.6(0.2-1.7)$ & $1.2(0.5-3.0)$ & $0.4(0.1-1.2)$ \\
\hline Maternal education ( $\geq$ secondary $=1$ ) & $1.3(0.7-2.7)$ & $1.9(1.0-3.8)$ & $1.0(0.5-2.2)$ \\
\hline Pregnancy order (range, $1-4)$ & $0.5(0.3-0.9)^{*}$ & $0.4(0.2-0.8)^{* *}$ & $0.4(0.2-0.8)^{* *}$ \\
\hline Man involved in pregnancy (Husband $=1$ ) & $3.7(1.4-10.1)^{*}$ & $2.0(0.9-4.2)$ & $4.9(1.8-13.1)^{* *}$ \\
\hline Perception of stigma (Yes=1) & $0.6(0.3-1.1)$ & $0.8(0.4-1.5)$ & $1.0(0.5-2.0)$ \\
\hline Intended pregnancy $(Y e s=1)$ & $2.4(0.9-6.4)$ & $1.9(0.9-3.8)$ & $1.3(0.5-3.0)$ \\
\hline Received prenatal care ( $\geq 4$ visits $=1$ ) & na & na & $6.5(2.8-15.3)^{* *}$ \\
\hline \multicolumn{4}{|l|}{ Intra-and interclass correlations } \\
\hline Intraclass (within-adolescent) & 0.12 & 0.46 & 0.45 \\
\hline Interclass (between-adolescent) & 0.03 & 0.00 & 0.06 \\
\hline \multicolumn{4}{|l|}{ No.ofcases } \\
\hline Pregnancies & 495 & 495 & 495 \\
\hline Adolescents & 388 & 388 & 388 \\
\hline Facilities & 56 & 56 & 56 \\
\hline
\end{tabular}

${ }^{*} \mathrm{p}<.05 .{ }^{* *} \mathrm{p}<.01$. Notes: $\mathrm{PMTCT}=$ prevention of mother-to-child transmission. ref=reference category. $\mathrm{na}=$ no applicable.

Health Survey (DHS) on adolescents from the four regions covered in our study to provide a basis for comparison (Table 1, page 144). The majority of the adolescents in the HIV-positive sample were aged 18-19 at the time of the survey (65\%), lived in Nairobi or Nyanza provinces (62\%) and had a primary education (68\%). Twelve percent were married or living with their partner. On average, the sample of HIV-positive adolescents was older than the DHS sample and were more likely to live in Nairobi or to be married or living with a partner; they were less likely to live in the Rift Valley.

\begin{tabular}{|c|c|c|}
\hline Variable & $\begin{array}{l}\text { Skilled } \\
\text { attendance† }\end{array}$ & $\begin{array}{l}\text { Postnatal/ } \\
\text { postabortion care }\end{array}$ \\
\hline Age at first pregnancy (in yrs.) & $1.0(0.8-1.2)$ & $1.0(0.7-1.3)$ \\
\hline \multicolumn{3}{|l|}{ Study site } \\
\hline Nyanza (ref) & 1.0 & 1.0 \\
\hline Coast & $1.1(0.5-2.3)$ & $0.2(0.0-0.7)^{*}$ \\
\hline Nairobi & $2.7(1.4-5.3)^{* *}$ & $0.6(0.2-1.7)$ \\
\hline Rift Valley & $1.3(0.6-2.9)$ & $0.2(0.0-0.8)^{*}$ \\
\hline Maternal education ( $\geq$ secondary $=1$ ) & $1.4(0.8-2.7)$ & $1.6(0.6-4.9)$ \\
\hline Pregnancy order (range, 1-4) & $0.6(0.4-0.9)^{*}$ & $0.6(0.3-1.2)$ \\
\hline Man involved in pregnancy (Husband $=1$ ) & $1.6(0.7-3.2)$ & $2.4(0.7-8.8)$ \\
\hline Perception of stigma (Yes=1) & $0.8(0.4-1.3)$ & $1.3(0.5-3.5)$ \\
\hline Intended pregnancy $(Y e s=1)$ & $1.4(0.7-2.8)$ & $1.3(0.4-4.4)$ \\
\hline Received prenatal care ( $\geq 4$ visits $=1$ ) & $4.7(2.4-9.0)^{* *}$ & $5.1(1.6-16.5)^{* *}$ \\
\hline \multicolumn{3}{|l|}{ Intra-and interclass correlations } \\
\hline Intraclass (within-adolescent) & 0.15 & 0.61 \\
\hline Interclass (between-adolescent) & 0.00 & 0.00 \\
\hline \multicolumn{3}{|l|}{ No.of cases } \\
\hline Pregnancies & 466 & 466 \\
\hline Adolescents & 369 & 369 \\
\hline Facilities & 54 & 54 \\
\hline
\end{tabular}

${ }^{*} \mathrm{p}<.05 .{ }^{* *} \mathrm{p}<.01$. †Refers to assistance by doctor, nurse or facility midwife at any pregnancy outcome Note: ref=reference category.

\section{Pregnancies to HIV-Positive Adolescents}

The majority of current or previous pregnancies in our sample were reported by adolescents aged 18 or older at the time of the survey (85\%-Table 2, page 145). In addition, nearly three-quarters (73\%) of the pregnancies had occurred among adolescents in Nyanza and Nairobi, which have the highest rates of HIV in the country. The majority of pregnancies (71\%) were reported by those with primary-level education. Nearly three-quarters (74\%) of the pregnancies were reported by adolescents who were not married or living with their partner at the time of the survey.

Although most of the pregnancies were reported by adolescents aged 18 or older at interview, the majority had occurred when the respondents were younger. For instance, $79 \%$ of the pregnancies reported had occurred among young women who had experienced their first pregnancy before age 18 . That $74 \%$ of the pregnancies to HIV-positive adolescents occurred among those who were not married or cohabiting at the time of the survey and that people other than husbands were responsible for $75 \%$ of the pregnancies indicates that the majority of these pregnancies occurred outside of marriage. In addition, nearly three-quarters (74\%) of the pregnancies among HIV-positive adolescents were unintended.

Although the adolescents received prenatal care in 84\% of their pregnancies, they made four or more visits during only $45 \%$ of the pregnancies. In addition, despite the fact that the provision of PMTCT services to HIV-positive adolescents should be part of prenatal care, the proportion of pregnancies for which these mothers received PMTCT services was significantly lower than the proportion for which they received prenatal care (67\% vs. 84\%; p<.01, not shown). A similar pattern appeared among HIV-positive female adolescents who were still pregnant at the time of the survey: They received prenatal care in $89 \%$ of pregnancies, while they received PMTCT services in only $74 \%$ of their pregnancies.

Most of the pregnancies resulted in a live birth (85\%); in $5 \%$ of cases, the adolescent was still pregnant (Table 2 ). The proportion of pregnancy outcomes for which adolescents received skilled attendance was significantly lower for miscarriages, stillbirths or abortion than for full-term or preterm live births (20\% vs. $79 \%$ and $78 \%$, respectively; $<<.01$, not shown). A similar pattern was observed for the proportion of pregnancy outcomes for which these adolescents received postnatal/postabortion care-33\% for miscarriages, stillbirths or abortion, $89 \%$ for full-term and $85 \%$ for preterm live births. HIV-positive adolescents received skilled care during delivery or pregnancy termination and postnatal/postabortion care for $73 \%$ and $83 \%$ of the pregnancies respectively (Table 2).

\section{Prenatal Care and PMTCT Services Utilization}

The odds of receiving prenatal care services were significantly lower among HIV-positive adolescents in Coast province than among those in Nyanza province (odds 
ratio, 0.3-Table 3) and for adolescents having higherorder pregnancies than for those having lower-order pregnancies (0.5). HIV-positive adolescents were more likely to have received prenatal care when the man responsible for the pregnancy was their husband than when it was some other person (3.7). However, adolescents from Coast province were significantly more likely than their counterparts from Nairobi province to have made four or more prenatal care visits ( $\mathrm{p}<.05$; not shown). In addition, HIVpositive adolescents were less likely to have made four or more visits for higher-order pregnancies than for lowerorder pregnancies (0.4).

HIV-positive adolescents from Nairobi had higher odds of receiving PMTCT services than those from Nyanza (odds ratio, 3.8), as well as those from Coast ( $\mathrm{p}<.05$; not shown) or Rift Valley provinces ( $\mathrm{p}<.01$; not shown). Adolescents were significantly less likely to have received PMTCT services for higher-order pregnancies than for lower-order pregnancies (0.4). However, they had higher odds of receiving PMTCT services when the person responsible for the pregnancy was their husband than when it was somebody else (4.9). Overall, adolescents were more likely to receive PMTCT services if they had made at least four prenatal care visits than if they had not (6.5).

\section{Skilled Assistance and Postnatal/Postabortion Care Utilization}

HIV-positive female adolescents from Nairobi were more likely to have received skilled assistance than their counterparts from Nyanza province (odds ratio, 2.7-Table 4) or Coast province ( $<<.05$; not shown). Overall, the odds of having received skilled care decreased as birth order increased (0.6). However, adolescents had significantly higher odds of receiving skilled assistance if they had made at least four prenatal care visits than if they had made fewer (4.7).

The odds of HIV-positive adolescents receiving postnatal/postabortion care services were significantly lower in Coast and Rift Valley provinces than in Nyanza (odds ratio, 0.2 each). However, mothers who had made four or more prenatal care visits had higher odds of receiving postnatal care services than those who had made fewer visits (5.1).

\section{DISCUSSION}

One of the major findings of this study is that the proportion of HIV-positive female adolescents who used PMTCT services was lower than the proportion who obtained prenatal care, despite national and international guidelines emphasizing the provision of such services to HIV-positive mothers as an integral component of prenatal care. ${ }^{32,33}$ One explanation could be the low proportion of adolescent mothers who made four or more prenatal care visits, given that this was associated with higher odds of receiving PMTCT services. It is possible that providers are able to offer more comprehensive services to those who make more frequent prenatal visits, given that not all services can be offered during one visit. Another explanation could be the lower odds of seeking care, including PMTCT services, for higher-order pregnancies than for lower-order pregnancies among adolescent mothers in the study. The high proportion receiving any prenatal care, the low proportion making four or more prenatal care visits, and the lower odds of seeking care for higher-order births have been observed among women in general. ${ }^{19,23,30}$ For HIVpositive women, however, nonuse or underuse of prenatal care has implications for vertical transmission of HIV. Our finding suggests that there is a need to ensure that PMTCT services are designed to meet the needs of HIV-positive adolescent mothers. There is evidence that HIV programs in many parts of Sub-Saharan Africa are organized around pediatric or adult care; too little attention is paid to meeting the reproductive health needs of those making the transition from childhood to adulthood. It also suggests that more effective information, education and communication programs are needed to encourage expectant mothers to make at least the four prenatal care visits recommended in national and international guidelines.

The second major finding of the study is the low use of certain maternal health care services, especially skilled attendance and postnatal/postabortion care for pregnancies that ended in miscarriage, stillbirth or abortion among HIV-positive female adolescents. This finding suggests that most of these outcomes occur under unsafe conditions, thereby exposing the adolescents to increased risks of maternal morbidity and mortality. However, this is not unique to HIV-positive adolescents. Unsafe abortion practices have been documented among female adolescents in Sub-Saharan Africa who are not HIV-infected. ${ }^{18,34}$ However, HIV-positive adolescents who receive treatment, care and support services visit clinics regularly. Ideally, these visits offer an opportunity to systematically screen HIVpositive young women for sexual and reproductive health information and service needs. Doing so will allow for early identification of pregnancy so that the adolescents can be referred to appropriate services. This finding also suggests the need for creating effective linkages between the HIV/AIDS centers and maternal and child health clinics to ensure comprehensive service provision for HIVpositive, pregnant adolescents.

The findings further suggest that to strengthen maternal and child health care services for this population, program planners need to take into account parity, paternity dynamics and regional variations in service use. Also, the finding that HIV-positive adolescent mothers from Nairobi were significantly more likely to receive PMTCT services and skilled attendance during delivery or pregnancy termination could be indicative of greater service availability and accessibility (in terms of distance from a facility and time needed to obtain the services) in the city than in other areas.

Our findings may be influenced by the study's limitations. First, the sample of HIV-positive adolescents was not randomly selected from the population. This was largely because of the sensitive nature of the study. Identifying 
and recruiting respondents through HIV/AIDS programs provided a convenient way of contacting them without exposing them to harm, psychological or otherwise. However, given the low rates of enrollment in HIV care and treatment in many East African settings, ${ }^{35,36}$ their experiences may not reflect the experiences of all HIV-positive adolescents in Kenya. The observed levels of maternal health care utilization could be higher or lower, depending on how different they are from their counterparts who do not receive services from the centers. In addition, the study did not capture information on other factors that might affect access to and utilization of services, such as urban or rural residence and household socioeconomic status. The estimation of multilevel logit models was, however, necessitated by the need to control for such unobserved characteristics.

In spite of these limitations, the study contributes to the literature by identifying some of the gaps in the use of maternal health care services by HIV-positive female adolescents in Kenya. To address these gaps, HIV/AIDS programs need to screen their adolescent clients for sexual activity and pregnancy to identify those in need of maternal health services, provide or refer those with such needs for appropriate services and create linkages with maternal and child health clinics to ensure that such clients receive all the relevant services.

\section{REFERENCES}

1. Clark S, Early marriage and HIV risks in Sub-Saharan Africa, Studies in Family Planning, 2004, 35(3):149-160.

2. Mturi AJ and Moerane W, Premarital childbearing among adolescents in Lesotho, Journal of Southern Africa Studies, 2001, 27(2):259-275.

3. Westoff CF, Trends in marriage and early childbearing in developing countries, DHS Comparative Reports, Calverton, MD, USA: ORC Macro, 2003, No. 5.

4. Manzini N, Sexual initiation and childbearing among adolescent girls in KwaZulu Natal, South Africa, Reproductive Health Matters, 2001, 9(17):44-52

5. Mensch BS, Singh S and Casterline JB, Trends in the timing of first marriage among men and women in the developing world, Policy Research Division Working Papers, New York: Population Council, 2005, No. 202.

6. Mensch BS, Grant MJ and Blanc AK, The changing context of sexual initiation in Sub-Saharan Africa, Population and Development Review, 2006, 32(4):699-727.

7. Gupta N and Mahy M, Adolescent childbearing in Sub-Saharan Africa: can increased schooling alone raise ages at first birth? Demographic Research, 2003, Vol. 8, Art. 4, pp. 93-106, <http:// www.demographic-research.org/volumes/vol8/4/>, accessed Aug. 26, 2010.

8. Kaufman CE, de Wet T and Stadler J, Adolescent pregnancy and parenthood in South Africa, Studies in Family Planning, 2001, 32(2): 147-160.

9. Mba CJ, Sexual behaviour and the risks of HIV/AIDS and other STDs among young people in Sub-Saharan Africa: a review, Research Review, 2003, 19(1):15-25

10. Katz K and Naré C, Reproductive health knowledge and use of services among young adults in Dakar, Senegal, Journal of Biosocial Science, 2002, 34(2):215-231.

11. Warenius LU et al., Nurse-midwives' attitudes towards adolescent sexual and reproductive health needs in Kenya and Zambia, Reproductive Health Matters, 2006, 14(27):119-128.

12. Wood K and Jewkes R, Blood blockages and scolding nurses: barriers to adolescent contraceptive use in South Africa, Reproductive Health Matters, 2006, 14(27):109-118.

13. Abou-Zahr CL and Wardlaw TM, Antenatal Care in Developing Countries: Promises, Achievements and Missed Opportunities: An Analysis of Trends, Levels and Differentials, 1990-2001, Geneva: World Health Organization (WHO) and United Nations Children's Fund, 2003.

14. Alam N, Teenage motherhood and infant mortality in Bangladesh: maternal age-dependent effect of parity one, Journal of Biosocial Science, 2000, 32(2):229-236

15. Chen XK et al., Teenage pregnancy and adverse birth outcomes: a large population based retrospective cohort study, International Journal of Epidemiology, 2007, 36(2):368-373

16. Conde-Agudelo A, Belizán JM and Lammers C, Maternal-perinatal morbidity and mortality associated with adolescent pregnancy in Latin America: cross-sectional study, American Journal of Obstetrics $\varepsilon$ Gynecology, 2005, 192(2):342-349.

17. Jolly MC et al., Obstetric risks of pregnancy in women less than 18 years old, Obstetrics \& Gynecology, 2000, 96(6):962-966.

18. Magadi M, Poor pregnancy outcomes among adolescents in South Nyanza region of Kenya, African Journal of Reproductive Health, 2006, 10(1):26-38.

19. Magadi MA, Agwanda AO and Obare FO, A comparative analysis of the use of maternal health services between teenagers and older mothers in Sub-Saharan Africa: evidence from Demographic and Health Surveys (DHS), Social Science \& Medicine, 2007, 64(6):13111325 .

20. Magadi M et al., Size of newborn and caesarean section deliveries among teenagers in Sub-Saharan Africa: evidence from DHS, Journal of Biosocial Science, 2007, 39(2):175-187.

21. Reynolds HW, Wong EL and Tucker H, Adolescents' use of maternal and child health services in developing countries, International Family Planning Perspectives, 2006, 32(1):6-16.

22. Fotso JC, Child health inequities in developing countries: differ ences across urban and rural areas, International Journal for Equity in Health, 2006, Vol. 5, Art. 9, <http://www.equityhealthj.com/content/ 5/1/9>, accessed June 26, 2007

23. Magadi MA, Zulu EM and Brockerhoff M, The inequality of maternal health care in urban Sub-Saharan Africa in the 1990s, Population Studies, 2003, 57(3):347-366.

24. Zere E et al., Equity in health and healthcare in Malawi: analysis of trends, BMC Public Health, 2007, Vol. 7, Art. 78, <http://www. biomedcentral.com/1471-2458/7/78>, accessed May 29, 2007.

25. Bond V, Chase E and Aggleton P, Stigma, HIV/AIDS and prevention of mother-to-child transmission in Zambia, Evaluation and Program Planning, 2002, 25(4):347-356.

26. Skinner D and Mfecane S, Stigma, discrimination and the implications for people living with HIV/AIDS in South Africa, Sahara Journal, 2004, 1(3):157-164

27. Birungi $\mathrm{H}$ et al., Sexual and reproductive health needs of adolescents perinatally infected with HIV in Uganda, FRONTIERS Final Report, Washington, DC: Population Council, 2008.

28. Birungi $\mathrm{H}$ et al., Sexual behaviour and desires among adolescents perinatally infected with human immunodeficiency virus in Uganda: implications for programming, Journal of Adolescent Health, 2009, 44(2):184-187.

29. Birungi $\mathrm{H}$ et al., Preventive service needs of young people perina tally infected with HIV in Uganda, AIDS Care, 2009, 21(6):725-731.

30. Kenya National Bureau of Statistics (KNBS) and ICF Macro, Kenya Demographic and Health Survey 2008-09, Calverton, MD, USA: KNBS and ICF Macro, 2010.

31. Rabe-Hesketh S and Skrondal A, Multilevel and Longitudinal Modeling Using Stata, second ed., College Station, TX, USA: Stata Press, 2008 . 
32. National AIDS \& STI Control Programme (NASCOP) and Ministry of Health $(\mathrm{MOH})$, Guidelines for Prevention of Mother-to-Child Transmission of HIV/AIDS in Kenya, third ed., Nairobi, Kenya: NASCOP and $\mathrm{MOH}, 2009$

33. WHO, Guidance on Global Scale-Up of the Prevention of Mother-toChild Transmission of HIV, Geneva: WHO, 2007.

34. Varga CA, Pregnancy termination among South African adolescents, Studies in Family Planning, 2002, 33(4):283-298

35. Unge $C$ et al., Reasons for unsatisfactory acceptance of antiretroviral treatment in the urban Kibera slum, Kenya, AIDS Care, 2008, 20(2): 146-149.

36. Lubega $\mathrm{M}$ et al., Policy and practice, lost in transition: reasons for high drop-out from pre-antiretroviral care in a resource-poor setting of eastern Uganda, Health Policy, 2010, 95(2-3):153-158.

\section{RESUMEN}

Contexto: Las adolescentes embarazadas y VIH-positivas en Kenia necesitan servicios de atención materna que tomen en cuenta su condición de VIH, dados los riesgos para la salud ocasionados por el VIH/SIDA y por el embarazo temprano. Sin embargo, la investigación sobre sus niveles de acceso y uso de dichos servicios es escasa.

Métodos: Para examinar el uso de los servicios de salud materna por adolescentes (edades de 15 a 19) VIH-positivas en Kenia, se analizaron datos recolectados en 2009 sobre los 506 embarazos de 393 adolescentes VIH-positivas, inscritas en programas de VIH/SIDA. Se utilizaron modelos logit multinivel para analizar las variables asociadas con el uso de los siguientes servicios provistos por profesionales de la salud: atención prenatal, prevención de la transmisión madre a hijo (PTMH) del VIH, atención en el parto o en los embarazos que terminan en abortos (espontáneos e inducidos), y atención postnatal e postaborto.

Resultados: El uso de servicios de PTMH fue menos común que el uso de servicios de atención prenatal en estas adolescentes VIH-positivas (67\% de los 506 embarazos vs 84\%); sin embargo, se realizaron cuatro o más visitas de atención prenatal en solamente el $45 \%$ de los embarazos. Además, el uso de atención provista por personal capacitado durante o después de un aborto inducido o espontáneo fue bajo (20\%). Las probabilidades de recibir servicios de PTMH y de ser atendido durante cualquier resultado del embarazo (nacido vivo, muerte fetal, aborto inducido o espontáneo) fueron más altas en Nairobi que en otras regiones (razones de momios de 3.8 y 2.7, respectivamente). Las adolescentes VIH-positivas tuvieron menor probabilidad de usar servicios de atención materna en los embarazos de alto orden que en los de bajo orden (0.4-0.6). Sin embargo, tuvieron mayor probabilidad de usar servicios de atención prenatal y de PTMH cuando su marido, en lugar de otro hombre, era el responsable del embarazo (3.7 y 4.9, respectivamente).

Conclusión: Las adolescentes embarazadas y VIH-positivas necesitan servicios de atención materna-incluida la atención de PTMH-que tomen en cuenta la paridad, la dinámica de la paternidad y las variaciones regionales en su uso.

\section{RÉSUMÉ}

Contexte: Étant donné les risques que présente le $\mathrm{VIH} /$ sida pour la santé et les risques des grossesses d'adolescentes en général, les adolescentes enceintes séropositives du Kenya ont besoin de services de santé maternelle qui tiennent compte de leur statut VIH. La recherche sur la question de leur accès et recours à ces services n'est cependant guère abondante.

Méthodes: Pour examiner le recours aux soins de santé maternelle, les données de grossesse recueillies en 2009 concernant 506 grossesses parmi 393 adolescentes séropositives de 15 à 19 ans inscrites aux programmes VIH/sida du Kenya ont été analysées. Des modèles logit multiniveaux ont servi à identifier les variables associées au recours aux prestations professionnelles suivantes: soins prénatals, prévention de la transmission mèreenfant (PTME) du VIH, l'assistance qualifiée à l'issue de la grossesse et soins postnatals ou après avortement.

Résultats: Le recours aux services PTME s'est avéré moins courant que celui aux prestations prénatales parmi les adolescentes séropositives (67\% des grossesses par rapport à 84\%). Parmi ces adolescentes, au moins quatre consultations prénatales ont eu lieu pour $45 \%$ des grossesses seulement. Le recours à une assistance qualifiée durant ou après un avortement spontané ou provoqué s'est aussi révélé faible (20\%). La probabilité de services PTME et d'assistance qualifiée à l'issue de la grossesse est plus grande à Nairobi que dans les autres régions (rapports de probabilités, 3,8 et 2,7, respectivement). Les adolescentes séropositives sont moins susceptibles de recourir aux prestations de santé maternelle aux rangs de grossesse supérieurs, par rapport aux rangs inférieurs $(0,4-0,6)$. Elles sont néanmoins plus susceptibles de recevoir des soins prénatals et des services PTME lorsque leur mari, plutôt qu'un autre intervenant, est responsable de la grossesse (3,7 et 4,9, respectivement).

Conclusion: Les adolescentes séropositives enceintes doivent bénéficier de prestations de santé maternelle-soins PTME compris-qui tiennent compte de leur parité, de la dynamique de la paternité et des variations régionales de recours aux services.

\section{Acknowledgments}

The study component in Rift Valley and Coast provinces was funded by the United States Agency for International Development (USAID). It was implemented by the Population Council through collaboration with the National AIDS and STI Control Programme in the Ministry of Health and agencies implementing phase II of the USAID-funded AIDS, Population and Health Integrated Assistance (APHIA II) programs in Kenya. The component in Nairobi and Nyanza provinces was funded by Plan Netherlands, the Royal Tropical Institute of the Netherlands and the Dutch Ministry of Foreign Affairs. It was implemented by Plan InternationalKenya. The views expressed in this paper are those of the authors.

Author contact:fonyango@popcouncil.org 